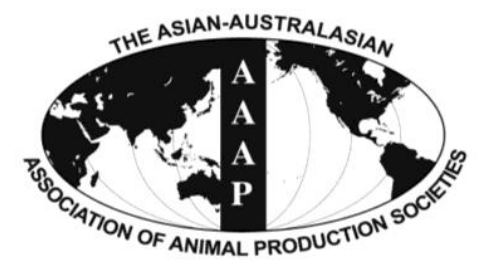

Asian Australas. J. Anim. Sci.

Vol. 26, No. 11 : 1518-1522 November 2013

http://dx.doi.org/10.5713/ajas.2013.13162

www.ajas.info

pISSN 1011-2367 elSSN 1976-5517

\title{
Association of Tyrosinase (TYR) and Tyrosinase-related Protein 1 (TYRP1) with Melanic Plumage Color in Korean Quails (Coturnix coturnix)
}

\author{
Ying Xu, Xiao-Hui Zhang, and You-Zhi Pang* \\ College of Animal Science, Henan University of Science and Technology, Luoyang, 471003, China
}

\begin{abstract}
TYR (Tyrosinase) and TYRP1 (Tyrosinase-related protein 1) play crucial roles in determining the coat color of birds. In this paper, we aimed to characterize the relationship of TYR and TYRP1 genes with plumage colors in Korean quails. The SNPs were searched by cDNA sequencing and PCR-SSCP in three plumage color Korean quails (maroon, white and black plumage). Two SNPs $(367 \mathrm{~T} \rightarrow \mathrm{C}$ and $1153 \mathrm{C} \rightarrow \mathrm{T}$ ) were found in the coding region of TYRP1 gene, but had no significant association with plumage phenotype in Korean quails. The expression of TYR was higher in black plumage quails than that in maroon plumage quails. In contrast, the expression of TYRP1 was lower in black plumage quails than that in maroon plumage quails. This study suggested that the melanic plumage color in Korean quails may be associated with either increased production of TYR or decreased production of TYRP1. (Key Words: Korean Quail, TYR, TYRP1, Polymorphism, Gene Expression)
\end{abstract}

\section{INTRODUCTION}

Many genes are involved in pigmentation, including the members of the tyrosinase-related protein (TRP) gene family, namely TYR (Tyrosinase), TYRP1 (Tyrosinaserelated protein 1) and TYRP2 (Tyrosinase-related protein 2) (Murisier et al., 2006). All these proteins share the same signaling sequence, two cysteine rich and a transmembrane domains, and most importantly, two $\mathrm{Cu}^{2+} / \mathrm{Zn}^{2+}$ binding sites responsible for their catalytic activities (Olivares and Solano, 2009; Ghanem and Fabrice, 2011). The previously study demonstrated that TYR gave rise to TYRP1, which then duplicated to form TYRP2 (Ray et al., 2007). They are thought to have the potential for functional polymorphisms, which could explain the natural variation in pigmentation phenotypes as well as the existence of several hypopigmented states (Huang et al., 2008).

The pathway for melanin biosynthesis includes a number of melanocyte-specific proteins (Randhawa et al., 2009). TYR is a multifunctional copper-containing glycoenzyme $(\sim 80 \mathrm{kDa})$, which plays a key role in the ratelimiting steps of this process (Ray et al., 2007). TYR acts on tyrosine to make dopaquinone (DQ), and there is then rapid addition of cysteine, as long as it is present (Tully,

\footnotetext{
* Corresponding Author: You-Zhi Pang. Tel: +86-0379-64282341, Fax: +86-0379-64635850, E-mail: pyzh2006@126.com Submitted Mar. 20, 2013; Accepted May 30, 2013; Revised Jul. 1, 2013
}

2007). DQ is a highly reactive intermediate that, after cyclization, undergoes a complex series of redox reactions leading to the production of melanin (Ito, 2006).

TYRP1 protein catalyzes the oxidation of 5, 6dihydroxyindole-2-carboxylic acid (DHICA) into indole-5, 6-quinone-2-carboxylic acid in the melanin biosynthesis pathway (Mondal et al., 2012). Moreover, TYRP1 gene promoter contains a motif, termed M-box, that can bind to the microphthalmia-associated transcription factor (MITF) (Ghanem and Fabrice, 2011). However, MITF is a master regulator in melanocyte proliferation, development, survival and melanoma formation (Wang et al., 2012). Additionally, studies have suggested that TYRP1 may help to stabilize tyrosinase (Kobayashi et al., 1998).

The Korean quails are widely distributed in China and have intricate color polymorphism. Plumage color is an important economic trait, which plays a crucial role in determining breed purity and phylogenesis. The coloration of hairs in mammals is mainly determined by the distribution of two types of melanin, eumelanin and pheomelanin, which produce brown to black and yellow to red colorations, respectively (Oribe et al., 2012). Of note, TYR and TYRP1 are involved in regulation and control of melanin synthesis. So in this study, the TYR and TYRP1 were selected as candidate genes to characterize the relationship of SNPs and expression with plumage color in Korean quails. 


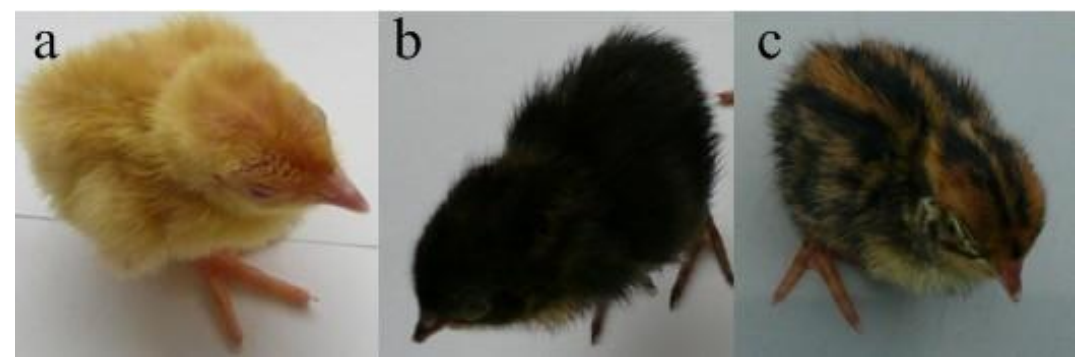

Figure 1. Korean quails with white (a), black (b) and maroon (c) plumage colors.

\section{MATERIALS AND METHODS}

\section{Animals and samples collection}

Korean quails (maroon, white and black plumage) were maintained at the quail breeding farm in Henan University of Science and Technology (Figure 1). The melanic plumage color mutation individuals were found in native Korean quails.

Twenty fertile eggs of each maroon, black and white plumage Korean quails were hatched and quail embryo skin tissues were collected at 12th day of hatching and frozen in liquid nitrogen immediately for total RNA extraction. A total of 84 blood samples were collected from the wing vein and stored at $-20^{\circ} \mathrm{C}$ for genome DNA extraction.

\section{Total RNA extraction and cDNA preparation}

Total RNA was isolated using the RNAiso puls kit (Takara, Dalian, China) according to the manufacturer's instructions. The quality of the total RNA was evaluated using the $1.2 \%$ agarose gel electrophoresis. After Dnase I (Takara, Dalian, China) treatment, total RNA was reverse transcribed using the PrimeScript RT reagent Kit (Takara, Dalian, China).

\section{Quantitative RT-PCR}

Quantitative RT-PCR (qRT-PCR) was performed on an
iQ Real Time PCR Detection Systems (Bio-Rad) using SYBR Premix Ex Taq II (Takara, Dalian, China). In all PCRs, a housekeeping gene (GAPDH) was used to monitor genomic DNA contamination and equality of sample loading. The total reaction volume for PCR was $20 \mu \mathrm{L}$. PCRs were performed as follows: 1 cycle of denaturation at $95^{\circ} \mathrm{C}$ for $3 \mathrm{~min}, 40$ cycles of denaturation at $94^{\circ} \mathrm{C}$ for $30 \mathrm{~s}$, annealing at appropriate temperature for $30 \mathrm{~s}$, extension/ fluorescence acquisition at $72^{\circ} \mathrm{C}$ for $25 \mathrm{~s}$, and a final extension at $72^{\circ} \mathrm{C}$ for $10 \mathrm{~min}$. Table 1 showed the primer sequences and annealing temperature.

\section{SNPs screening}

The cDNA of TYR and TYRP1 was cloned by TYR2 and TYRP2 primers from ten maroon, black and white plumage Korean quails respectively, and then sequenced individually. The obtained sequences were aligned by SeqMan (DNAStar 6.0 software) to search SNPs based on the difference between sequences. The SNPs were screened in three plumage color groups by PCR-SSCP using the TYRP3 and TYRP4 primers.

\section{Statistical analysis}

Genotype and allele frequencies of polymorphic TYRP1 were calculated by the direct counting method. The HardyWeinberg equilibrium was evaluated for each SNP using the

Table 1. The information of TYR and TYRP1 primers ${ }^{1}$

\begin{tabular}{|c|c|c|c|c|}
\hline Primer name & Primer sequence (5'-3') & $\operatorname{Tm}\left({ }^{\circ} \mathrm{C}\right)$ & Product length (bp) & Methods \\
\hline \multirow[t]{2}{*}{ TYR1 } & TCCCCAGCAAGGACTATG & 55 & 213 & qRT-PCR \\
\hline & GAAAAGCACGATGCCAAG & & & \\
\hline \multirow[t]{2}{*}{ TYR2 } & TCCCCAGCAAGGACTATG & 52 & 1,183 & Gene cloning \\
\hline & CATCACTGAGATACTGGAGG & & & \\
\hline \multirow[t]{2}{*}{ TYRP1 } & TGGATGGACTGGACCTAC & 52 & 158 & qRT-PCR \\
\hline & CTTCACGTCTCCTTGTGG & & & \\
\hline \multirow[t]{2}{*}{ TYRP2 } & TGGATGGACTGGACCTAC & 56 & 1,278 & Gene cloning \\
\hline & GCCATCTCTTCAAACGACAG & & & \\
\hline \multirow[t]{2}{*}{ TYRP3 } & TATGCTACAGGATCCCAG & 49 & 166 & PCR-SSCP \\
\hline & ACTTTCACACAGCACACG & & & \\
\hline \multirow[t]{2}{*}{ TYRP4 } & CTGCACTCGTTCTTGTTG & 50 & 94 & PCR-SSCP \\
\hline & GTGAGAAGAGGCTGATGC & & & \\
\hline \multirow[t]{2}{*}{ GAPDH } & TGCCGTCTGGAGAAACC & 55 & 160 & qRT-PCR \\
\hline & CAGCACCCGCATCAAAG & & & \\
\hline
\end{tabular}

${ }^{1}$ TYR = Tyrosinase, TYRP1 = Tyrosinase-related protein 1. 
chi-square test. In addition, the relative expression levels of TYR and TYRP1 genes were determined by the comparative cycle threshold $\left(\Delta^{\mathrm{CT}}\right)$ method. The gene expression in different plumage color quails was analyzed by one-way ANOVA followed by Bonferroni test for pair wise comparison.

\section{RESULTS AND DISCUSSION}

\section{The polymorphism of TYRP1 with the plumage/skin color changes}

Two SNPs were found in TYRP1 gene. The first SNP was a base substitution $(\mathrm{T} \rightarrow \mathrm{C})$ at 367 bp of coding region in exon 2, which changed a leucine to a serine in protein sequence. Genotyping of 84 Korean quails was tested by PCR-SSCP and three kinds of genotypes (AA, AB, and BB) were found in this population (Figure 2). The second SNP was also a base substitution $(\mathrm{C} \rightarrow \mathrm{T})$ at $1,153 \mathrm{bp}$ of coding region in exon 6 , which changed a threonine to a isoleucine in the protein sequence. Genotyping of 61 Korean quails were tested by the same method and three genotypes (AA, $\mathrm{AB}$, and $\mathrm{BB}$ ) were found in this population (Figure 3 ).

According to the chi-square criterion, no significant associations were found between the mutations of TYRP1 gene and the plumage color $(p>0.05)$. Furthermore, the distribution of three genotypes was not within HardyWeinberg equilibrium in the tested population $(\mathrm{p}>0.05)$. The calculation of allele frequencies for each SNP is listed in Table 2 , respectively.

It has been reported that mutations in TYRP1 alter the

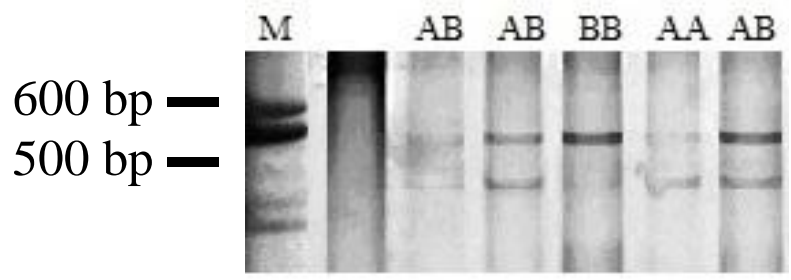

Figure 2. Genotyping of the T/C mutation at 367 bp by PCRSSCP. Three kinds of genotypes (AA, AB, BB) were found in Korean quails. $\mathrm{M}$ is the $600 \mathrm{bp}$ size marker.

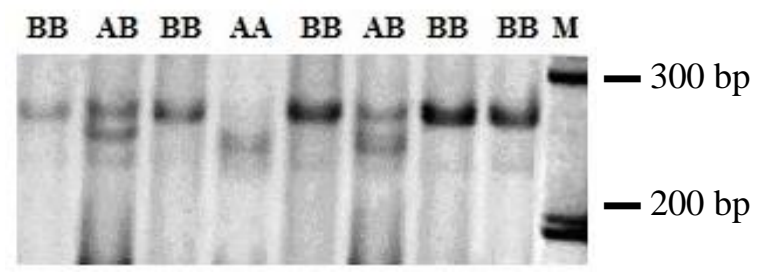

Figure 3. Genotyping of the $\mathrm{C} / \mathrm{T}$ mutation at 1153 bp by PCRSSCP. Three kinds of genotypes (AA, AB, BB) were found in Korean quails. $\mathrm{M}$ is the $600 \mathrm{bp}$ size marker.

type of pigment. A screen of the entire coding sequence of TYRP1 in roux and wild-type Japanese quails revealed a non-synonymous T/C substitution in exon 3, leading to a Phe282Ser mutation (Nadeau et al., 2007). This mutation had been reported to associate with the plumage color in Japanese quails. Interestingly, the Phe282Ser mutation of TYRP1 was not found in Korean quails. In this work, we were able to identify two non-synonymous substitutions at exon 2 and exon 6, respectively. But, there was no significant association with the plumage color in Korean quails. In addition, a $\mathrm{G} \rightarrow \mathrm{T}$ transversion in TYRP1 at nucleotide position 869 was perfectly associated with coat color in sheep (Gratten et al., 2007). A SNP of TYRP1 was shown to be associated with the brown coat color in dogs (Schmutz et al., 2002). In Chinese indigenous pigs, a 6-bp deletion (TGGGTA) in the TYRP1 gene was found to be the causative mutation for the brown colouration (Ren et al., 2011). In summary, in the present study, there was no evidence that particular SNPs were associated with plumage color in Korean quails.

\section{The polymorphism of TYR with the plumage/skin color changes}

Compared with TYRP1 gene, no mutation was found in TYR gene by cDNA sequencing. A previous study has been reported that TYR is one of the important enzymes that catalyze the synthesis of melanin in melanocytes (Sturm et al., 2001). In humans, the Arg402Gln mutation of TYR has been described to be associated with eye color and skin type (Nan et al., 2009). In albino cats, a cytosine deletion in TYR gene was found at 975 bp in exon 2, which caused a

Table 2. The genotypes and allele frequencies of the mutations

\begin{tabular}{|c|c|c|c|c|c|c|c|}
\hline \multirow{2}{*}{ SNPs } & \multirow{2}{*}{ Quail groups } & \multirow{2}{*}{ Number } & \multicolumn{3}{|c|}{ Genotypes } & \multicolumn{2}{|c|}{ Allele Frequencies } \\
\hline & & & $\mathrm{AA}$ & $\mathrm{AB}$ & $\mathrm{BB}$ & A & $\mathrm{B}$ \\
\hline \multirow[t]{3}{*}{$367 \mathrm{~T} / \mathrm{C}^{1}$} & Maroon quail & 13 & 3 & 0 & 10 & 0.2308 & 0.7692 \\
\hline & Black quail & 41 & 6 & 29 & 6 & 0.5000 & 0.5000 \\
\hline & White quail & 30 & 7 & 21 & 2 & 0.5833 & 0.4167 \\
\hline \multirow[t]{3}{*}{$1153 \mathrm{C} / \mathrm{T}^{2}$} & Maroon quail & 13 & 2 & 9 & 2 & 0.5000 & 0.5000 \\
\hline & Black quail & 25 & 14 & 11 & 0 & 0.7800 & 0.2200 \\
\hline & White quail & 23 & 5 & 12 & 6 & 0.4783 & 0.5217 \\
\hline
\end{tabular}

${ }^{1}$ A base substitution $(\mathrm{T} \rightarrow \mathrm{C})$ at $367 \mathrm{bp}$ of coding region in exon $2 .{ }^{2}$ A base substitution $(\mathrm{C} \rightarrow \mathrm{T})$ at 1,153 bp of coding region in exon 6 . 

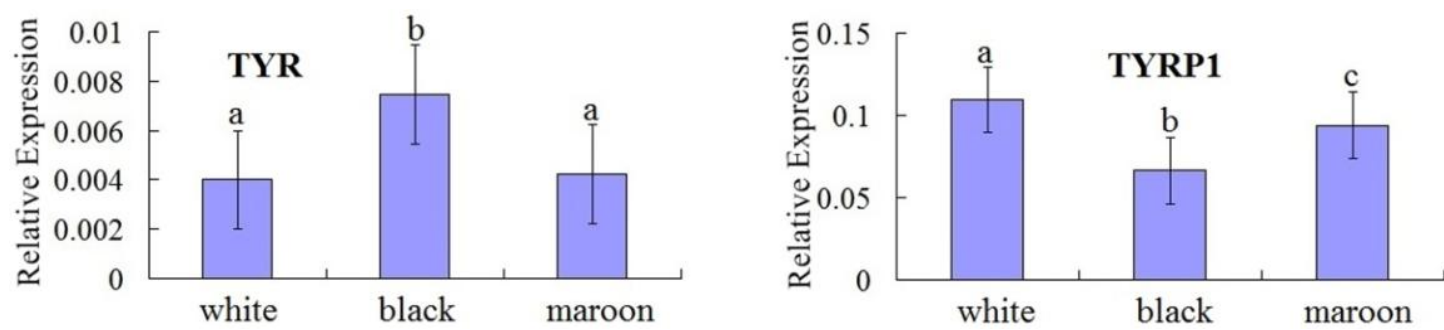

Figure 4. The expression of TYR and TYRP1 in skin tissues of Korean quail embryos. TYR = Tyrosinase, TYRP1 = Tyrosinase-related protein 1 . Treatments headed by the same letter denotes no significant difference $(p>0.05)$.

frame shift resulting in a premature stop codon nine residues downstream from the mutation (Imes et al., 2006). On the other hand, mutations within the TYR gene have been shown to cause oculocutaneous albinism (OCA), a developmental disorder with an autosomal recessive mode of inheritance (Ray et al., 2007). Comparison of TYR coding regions in the OCA buffalo identified a single-base substitution at nucleotide 1,431 ( $\mathrm{G}$ to $\mathrm{A}$ ), which caused the conversion of a tryptophan into a stop codon (Damé et al., 2012). Therefore, the mutations in this gene can affect coat color in many species of mammals. But in Korean quails, no SNP was detected in TYR gene coding region.

\section{The expression of TYR and TYRP1 with the plumage/ skin color}

The expression of TYR and TYRP1 produces significant differences between the three kinds of plumage color Korean quails (Figure 4). The relative expression level of TYR mRNA in skin tissues was higher in maroon Korean quails than that in white Korean quails, and was significantly higher in black Korean quails. On the other hand, the relative expression level of TYRP1 mRNA in skin tissues was lower in maroon Korean quails than that in white Korean quails, and was significantly lower in black Korean quails.

In cells expressing both TYR and TYRP1 or TYR and DCT, the total amount of melanin increased substantially more than that in cells expressing TYR alone ( $\mathrm{Rad}$ et al., 2004). From the Western blot analysis, reduce of melanin contents and TYR activity were associated with attenuated amounts of TYR and TYRP1 protein levels (Yu and Kim, 2010). It is noteworthy that there was no difference in TYRP1 expression between dark and light Soay sheep (Gratten et al., 2007). In Japanese quail, the expression of TYRP1 was not significantly different between roux and wild-type birds (Nadeau et al., 2007). In contrast, the expression of TYR and TYRP1 showed significant difference among the three Korean quails with different plumage color. In ducks, TYR and TYRP1 were not expressed in white feather bulbs but in black feather bulbs (Li et al., 2012). Meanwhile, similar phenomenon are found in many species of mammals (Guibert et al., 2004; Okomo-
Adhiambo et al., 2012).

\section{CONCLUSIONS}

Two SNPs were found in TYRP1 gene coding region, but there were no significant association with the plumage color in Korean quails. No SNP was found in the TYR gene coding region. The expression of TYR and TYRP1 genes produces a significant difference among the maroon, white and black plumage Korean quails, which indicated the black plumage color in Korean quails may be caused by either increased production of TYR or decreased production of TYRP1.

\section{ACKNOWLEDGEMENTS}

We would like to acknowledge the financial support of Henan key science and technology research projects (082102130002).

\section{REFERENCES}

Damé, M. C. F., G. M. Xavier, J. P. Oliveira-Filho, A. S. Borges, H. N. Oliveira, F. Riet-Correa, and A. L. Schild. 2012. A nonsense mutation in the tyrosinase gene causes albinism in water buffalo. BMC Genet. 13:62.

Ghanem, G. and J. Fabrice. 2011. Tyrosinase related protein 1 (TYRP1/gp75) in human cutaneous melanoma. Mol. Oncol. 5: $150-155$

Gratten, J., D. Beraldi, B. V. Lowder, A. F. McRae, P. M. Visscher, J. M. Pemberton, and J. Slate. 2007. Compelling evidence that a single nucleotide substitution in TYRP1 is responsible for coat-colour polymorphism in a free-living population of Soay sheep. Proc. R. Soc. B. 274:619-626.

Guibert, S., M. Girardot, H. Leveziel, R. Julien, and A. Oulmouden. 2004. Pheomelanin coat colour dilution in French cattle breeds is not correlated with the TYR, TYRP1 and DCT transcription levels. Pigment Cell Res. 17:337-345.

Huang, Y. H., T. H. Lee, K. J. Chan, F. L. Hsu, Y. C. Wu, and M. H. Lee. 2008. Anemonin is a natural bioactive compound that can regulate tyrosinase-related proteins and mRNA in human melanocytes. J. Dermatol. Sci. 49:115-123.

Imes, D. L., L. A. Geary, R. A. Grahn, and L. A. Lyons. 2006. Albinism in the domestic cat (Felis catus) is associated with a tyrosinase (TYR) mutation. Anim. Genet. 37:175-178. 
Ito, S. 2006. Encapsulation of a reactive core in neuromelanin. Proc. Natl. Acad. Sci. USA. 103:14647-14648.

Kobayashi, T., G. Imokawa, D. C. Bennett, and V. J. Hearing. 1998. Tyrosinase stabilization by TYRP1 (the brown locus protein). J. Biol. Chem. 273:31801-31805.

Li, S., C. Wang, W. Yu, S. Zhao, and Y. Gong. 2012. Identification of genes related to white and black plumage formation by RNA-Seq from white and black feather bulbs in ducks. Plos. One. 7:e36592.

Mondal, M., M. Sengupta, S. Samanta, A. Sil, and K. Ray. 2012. Molecular basis of albinism in India: Evaluation of seven potential candidate genes and some new findings. Gene 511: 470-474.

Murisier, F., S. Guichard, and F. Beermann. 2006. A conserved transcriptional enhancer that specifies TYRP1 expression to melanocytes. Dev. Biol. 298:644-655.

Nadeau, N. J., N. I. Mundy, D. Gourichon, and F. Minvielle. 2007. Association of a single-nucleotide substitution in TYRP1 with roux in Japanese quail (Coturnix japonica). Anim. Genet. 38: 609-613.

Nan, H., P. Kraft, D. J. Hunter, and J. Han. 2009. Genetic variants in pigmentation genes, pigmentary phenotypes, and risk of skin cancer in Caucasians. Int. J. Cancer 125:909-917.

Okomo-Adhiambo, M., A. Rink, W. M. Rauw, and L. GomezRaya. 2012. Gene expression in Sinclair swine with malignant melanoma. Animal 6:179-192.

Olivares, C. and F. Solano. 2009. New insights into the active site structure and catalytic mechanism of tyrosinase and its related proteins. Pigment Cell. Melanoma. Res. 22:750-760.

Oribe, E., A. Fukao, C. Yoshihara, M. Mendori, K. G. Rosal, S. Takahashi, and S. Takeuchi. 2012. Conserved distal promoter of the agouti signaling protein (ASIP) gene controls sexual dichromatism in chickens. Gen. Comp. Endocrinol. 177:231237.
Rad, H. H., T. Yamashita, H. Y. Jin, K. Hirosaki, K. Wakamatsu, S. Ito, and K. Jimbow. 2004. Tyrosinase-related proteins suppress tyrosinase-mediated cell death of melanocytes and melanoma cells. Exp. Cell Res. 298:317-328.

Randhawa, M., T. Huff, J. C. Valencia, Z. Younossi, V. Chandhoke, V. J. Hearing, and A. Baranova. 2009. Evidence for the ectopic synthesis of melanin in human adipose tissue. FASEB. J. 23: 835-843.

Ray, K., M. Chaki, and M. Sengupta, 2007. Tyrosinase and ocular diseases: Some novel thoughts on the molecular basis of oculocutaneous albinism type 1. Prog. Retin. Eye Res. 26:323358.

Ren, J., H. Mao, Z. Zhang, S. Xiao, N. Ding, and L. Huang. 2011. A 6-bp deletion in the TYRP1 gene causes the brown colouration phenotype in Chinese indigenous pigs. Heredity 106:862-868.

Schmutz, S. M., T. G. Berryere, and A. D. Goldfinch, 2002. TYRP1 and MC1R genotypes and their effects on coat color in dogs. Mamm. Genome 13:380-387.

Sturm, R. A., R. D. Teasdale, and N. F. Box. 2001. Human pigmentation genes: identification, structure and consequences of polymorphic variation. Gene 277:49-62.

Tully, G. 2007. Genotype versus phenotype: Human pigmentation. Genetics 1:105-110.

Wang, P., Y. Li, W. Hong, J. Zhen, J. Ren, Z. Li, and A. Xu, 2012. The changes of microRNA expression profiles and tyrosinase related proteins in MITF knocked down melanocytes. Mol. Biosyst. 8:2924-2931.

Yu, J. S. and A. K. Kim. 2010. Effect of combination of taurine and azelaic on antimelanogenesis in murine melanoma cells. J. Biomed. Sci. 17:S45. 